\title{
6. UNDERWAY SURVEYS, LEG 37
}

\author{
Robert J. Iuliucci and James M. Hall, Department of Geology, \\ Dalhousie University, Halifax, Nova Scotia, Canada \\ and \\ William G. Melson, Department of Mineral Sciences, National Museum of Natural History, \\ Smithsonian Institution, Washington, D.C.
}

\section{INTRODUCTION}

While in transit from Recife, Brazil, to the Leg 37 drill site locations on the Mid-Atlantic Ridge southwest of the Azores, and then to Dublin, Ireland, Glomar Challenger collected $7200 \mathrm{~km}$ of underway geophysical profiles, including $12-\mathrm{kHz}$ depth recordings, earth's total field magnetometer measurements, and continuous seismic reflection profiles.

An index map (Figure 1a, b) showing the location of the track, is annotated in GMT hour and date. The large numerals along the track locate the portions of track illustrated in the text. Base contours are from the Bathymetric Atlas of the Atlantic, Caribbean, and Gulf of Mexico (Uchupi, 1971). The track was extracted from navigation information and plots prepared by the Underway Data Processing Group, Scripps Institution of Oceanography.

The underway geophysical data presented (Figures 2 to 10) consist of photographic reproductions of original seismic reflection records with the corresponding magnetic anomaly profiles. Horizontal scale is GMT time, and kilometers from the start of record collection; vertical scale is reflection time in seconds for the seismic profiles, and gammas for the magnetic profiles. Magnetic anomalies were extracted from total field measurements following the visual fitting of a linear regional magnetic gradient over the segments in question. The vertical exaggeration for the reflection profiles is 60 to 1 for Figures 2 to 6 , and 75 to 1 for Figures 7 to 10 , at $18.5 \mathrm{~km} / \mathrm{hr}$ (10 knots), but varies with the ship's speed.

Distant ports from the Leg 37 area of interest dictated that the ship's track follow the quickest route to and from the drill sites and this was generally along the flanks and parallel to the axis of the Mid-Atlantic Ridge, therefore definitive profiles of the ridge and surrounding physiographic provinces were rare. However, good perpendicular crossings of the large transverse faults and fracture zones of the Central and North Atlantic were made, and it is to these, with a view toward future drilling site identification, that we mainly devote our attention. The results of detailed surveying in the vicinity of the Leg 37 sites appear elsewhere in this volume. Underway data collected on Leg 37 not reported in this volume are available from the Deep Sea Drilling Project.

\section{INDIVIDUAL FEATURES OF INTEREST}

Political considerations prevented collection of data within $320 \mathrm{~km}$ of Brazilian territory, and consequently the continental margin off northeastern South America was not profiled.

Recording began in the deep waters of the Ceara Abyssal Plain (Figure 2). The track crossed to the west of the main part of the St. Paul's Fracture Zone which here appears as a large, up-thrust block (1930-2030 hr, 7 June), marking the northern boundary of the abyssal plain succeeded to the north by a general rise in basement elevation of approximately a kilometer. The magnetic signature of the fracture zone is not pronounced. There is a change in the general level of the magnetic field, which is about $40 \gamma$ more positive to the north of the prominent ridge crossed at $2000 \mathrm{hr}$ than to the south of the ridge. The magnetic topography is also enhanced to the north of this ridge, which is consistent with magnetic layer 2 being about a kilometer shallower than it is to the south of the ridge. It is notable that the ridge itself does not have a magnetic signature. This could be the result of it being composed of a fresh essentially nonmagnetic basic or ultrabasic intrusive material.

As the Mid-Atlantic Ridge was crossed obliquely from the American to the African plates (Figure 3), water depth and sediment thickness gradually decreased until the ridge crest was crossed, $0730-1100 \mathrm{hr}$, 9 June. Magnetic anomalies are attenuated in this area, even over the alternative positions of the median valley $(0930,1100,9$ June). This is likely to be a consequence of approximately north-south geological strike and near-horizontal magnetization. A major fracture zone is located at not more than $10 \mathrm{~km}$ north of the supposed position of the ridge axis crossing. In fact, it is impossible to separate with confidence strong relief due to fracture zone tectonics from crested mountain type topography. However, we note that the deepest rifts in this region, regardless of their origin, are strikingly barren of sediment, indicating that an obstruction to the west has prevented the flow of continental sediments from the Amazon River from reaching into these valleys and that this portion of the fault complex is probably not linked directly to the Vema Fracture Zone proper. Slightly further north, from $1500 \mathrm{hr}$ onward, multilayered sedimentary horizons of probably terrigenous origin mark the western extension of the Vema Fracture Zone.

The eastern extension of the Kane Fracture (Figure 4) was encountered beginning at $1030 \mathrm{hr}, 13 \mathrm{June}$. The crossing of a deep associated with it produced the deepest soundings of Leg 37 (1930-2000 hr, 13 June) 8.9 $\mathrm{sec}$ to the flat-floored, sediment-filled valley, and at least $9.3 \mathrm{sec}$ to acoustic basement. The magnetic 


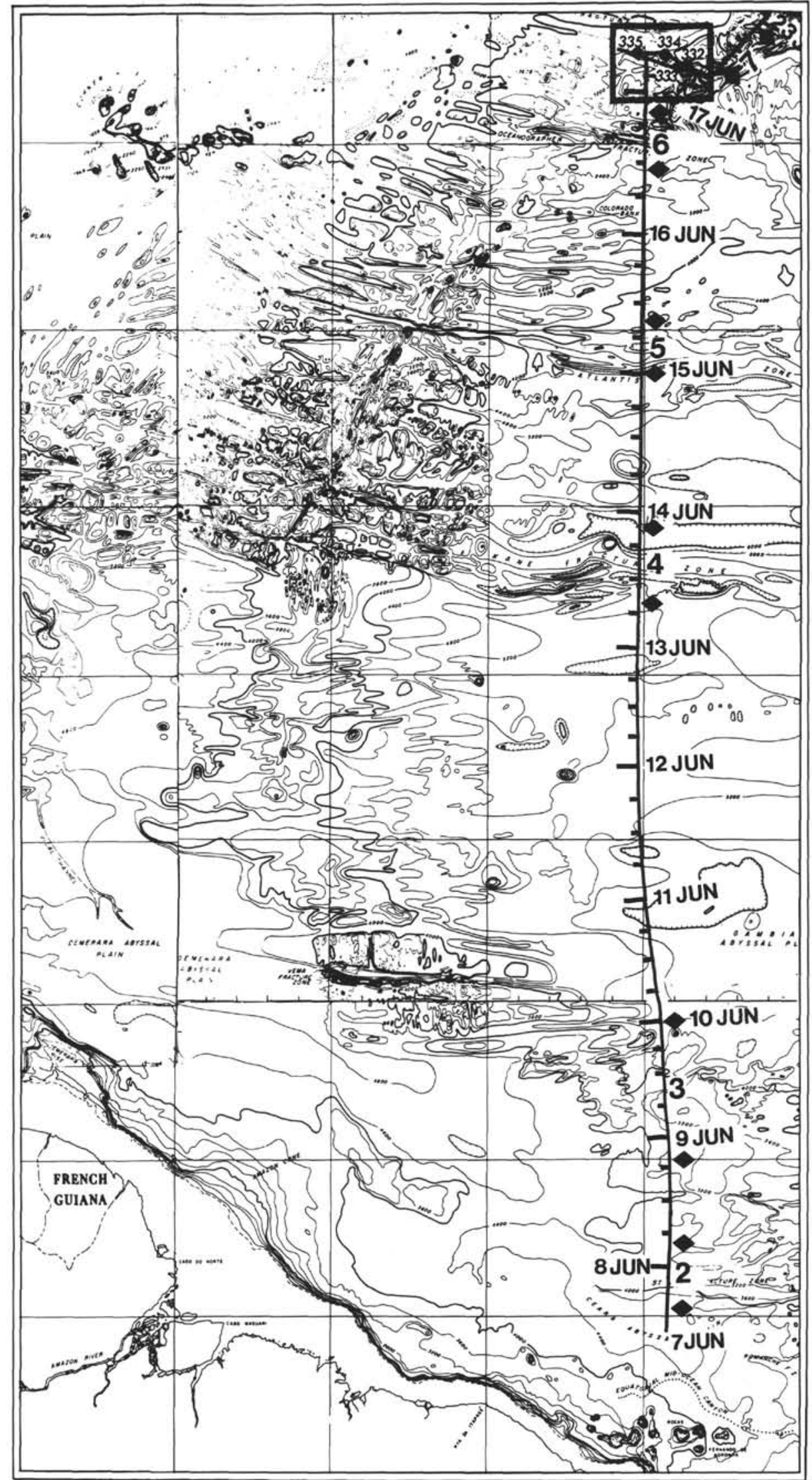

Figure 1a. Track chart for Leg 37 of Glomar Challenger from Recife, Brazil, to the drill site area. Track is annotated every 6 hours GMT time and each change of day. The large numerals along the track locate the portions of the track illustrated in the text. 


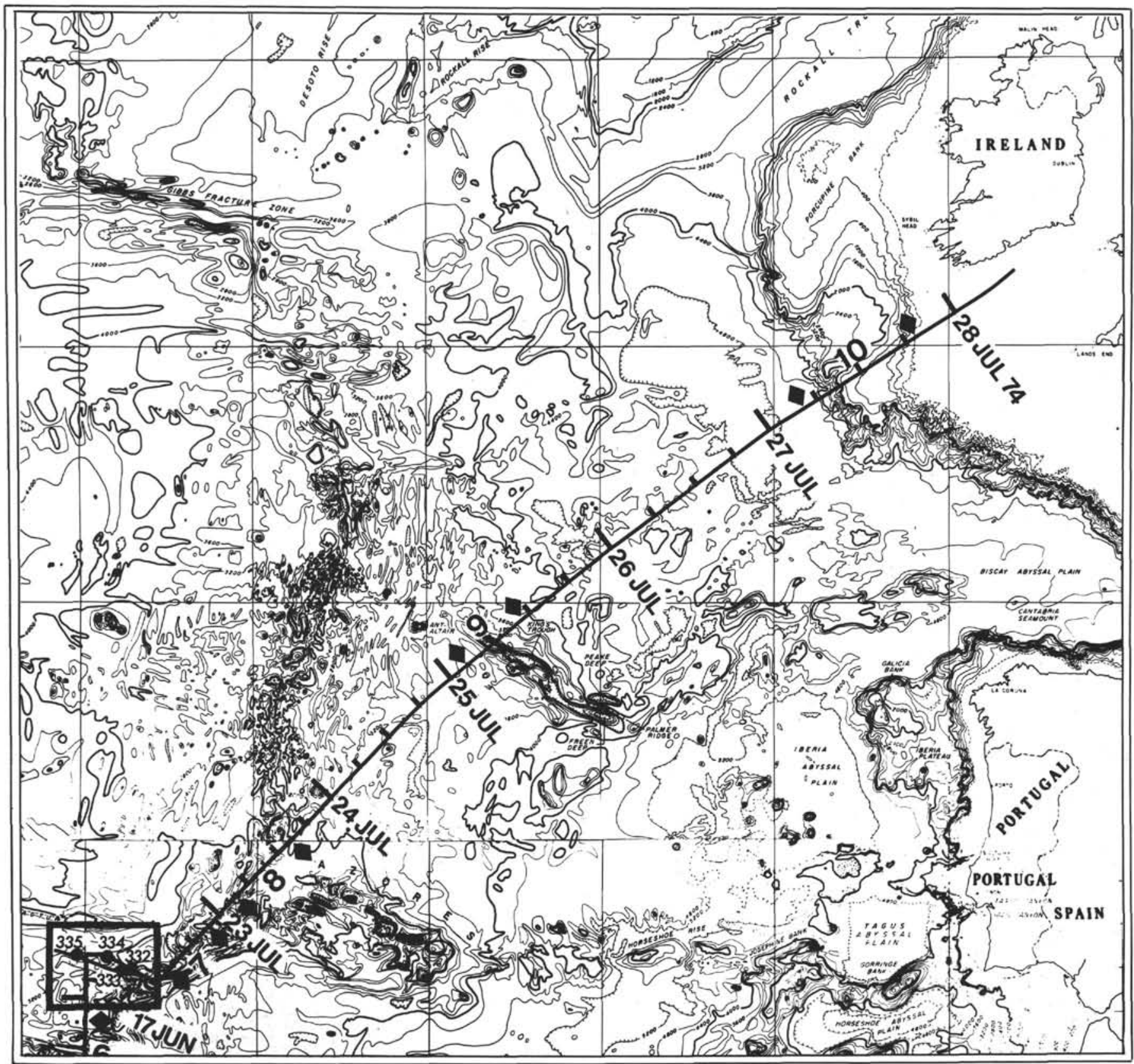

Figure 1b. Track chart for Leg 37 of Glomar Challenger from drill site area to Dublin, Ireland. Track is annotated every 6 hours GMT time and each change of day. The large numerals along the track locate the portions of the track illustrated in the text.

anomaly profile consists of a series of small amplitude features, which barely exceed a maximum of $200 \gamma$ peak to peak, and which fail to show obvious correlation with bathymetric features.

The eastern extension of the Atlantic Fracture Zone (Figure 5), crossed between 0000 and 0200 hr, 15 June, is well defined here with distinct sediment-covered, flat steps. Providing the sections are similar on both sides of the fracture zone, the presence of an adequately thick sediment layer to stabilize the bottom-hole assembly and the steplike nature of the fracture here would make this an excellent location for a set of single bit, deep penetration attempts. Perhaps one site could be located at the southern end of the upper step, another at the northern edge of the middle step, and a third on the southern edge of the deepest step (arrows), enabling succeedingly deeper penetration into basement without the need for re-entry. Again magnetic anomalies are weakly developed over the fracture zone. However, in contrast with crossings of the more southerly fracture zones, anomaly sense on the Atlantis Fracture Zone crossing correlates well with bathymetry. Thus, positive anomalies are strongly associated with bathymetric peaks and negative anomalies with bathymetric lows. This relationship suggests that the basement rocks in this area are normally magnetized with fairly steep inclination. Remanent magnetization is favored as induced magnetization, inclined at the dipole field value 

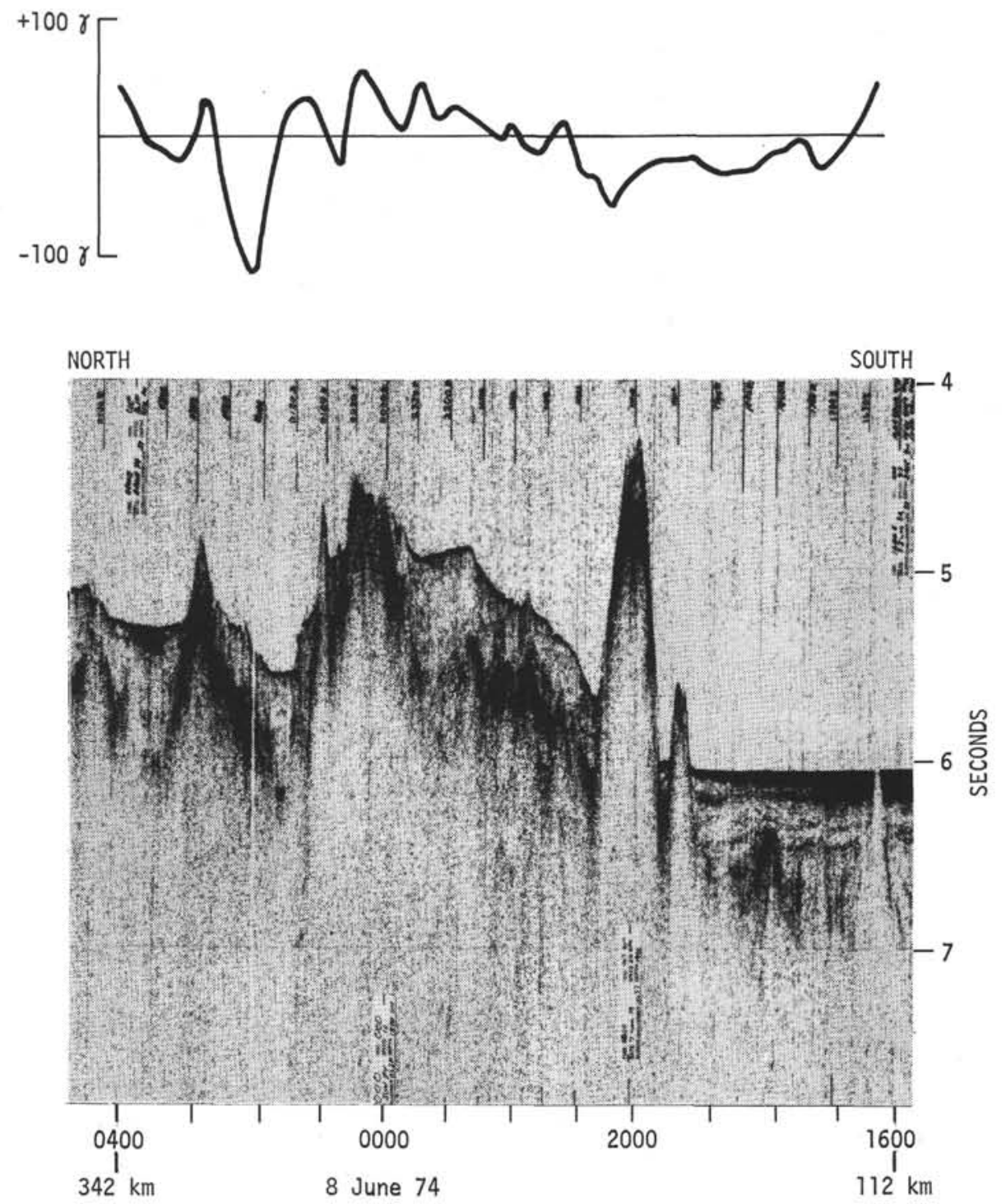

Figure 2. Glomar Challenger, Leg 37, seismic reflection and magnetic anomaly profiles in vicinity of St. Paul's Fracture Zone.

of $+48^{\circ}$ for the latitude of the fracture zone crossing would result in a less clear relationship between anomaly peaks and troughs and bathymetric highs and lows.

Glomar Challenger's track crossed the Oceanographer Fracture Zone (Figure 6) at between 1430 and $1830 \mathrm{hr}, 16$ June, where it separates two ridge crest segments, thus taking the track back from the African plate onto the American plate. The Oceanographer Fracture Zone here is a deep, broad rift and is the single most outstanding bathymetric feature crossed during the leg. A brief stop to test an acoustic beacon accounts for the discontinuity of the record and the loss of resolution on the floor of the central fracture. A very strong negative anomaly is associated with the ridge forming the north wall of the rift which was crossed between 1700 and $1830 \mathrm{hr}, 16$ June. With a peak to peak amplitude of $1045 \gamma$, the magnitude of this anomaly was only exceeded by the central anomaly of a ridge crest crossing in the relatively shallow water of the Azores Plateau (Figure 8). The form of the anomaly suggests reversed remanent magnetization as the source. Remanence inclination must be rather shallower than the value of $-54^{\circ}$ for a dipole field at the latitude of the fracture zone. The high amplitude of the anomaly suggests a very strong intensity of magnetization. The reverse magnetization of the ridge suggests that it does not consist of the typical basalts of Layer 2 since very strong magnetization is found only for very young unoxidized basalt of the Brunhes normal polarity epoch (Detrick and Lynn, 1975).

The Pico Fracture Zone (Figure 7) was crossed between 1430 and $1630 \mathrm{hr}, 22$ July. On this crossing the fracture zone appears as a 1600-meter deep asymmetrical depression about $35 \mathrm{~km}$ in width. Sediment appears to be present in two small ponds within the depression. The ponds are on the lower slopes of the more gently inclined south wall of the depression. The magnetic profile across the fracture zone consists of a series of anomalies of typical amplitudes for the latitude of the fracture zone. Individual anomalies do 


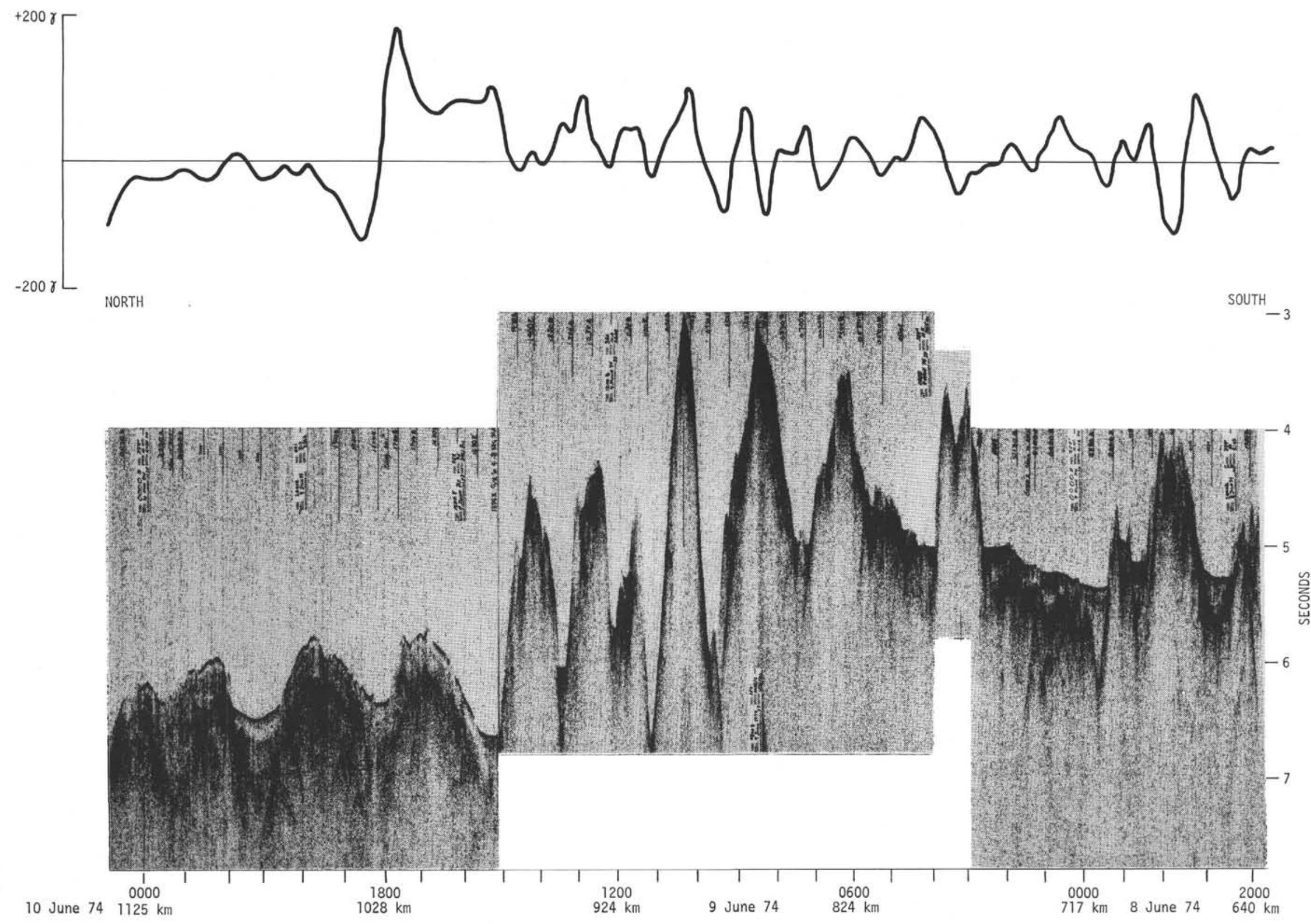

Figure 3. Glomar Challenger, Leg 37, seismic reflection and magnetic anomaly profiles in vicinity of Vema Fracture Zone. 

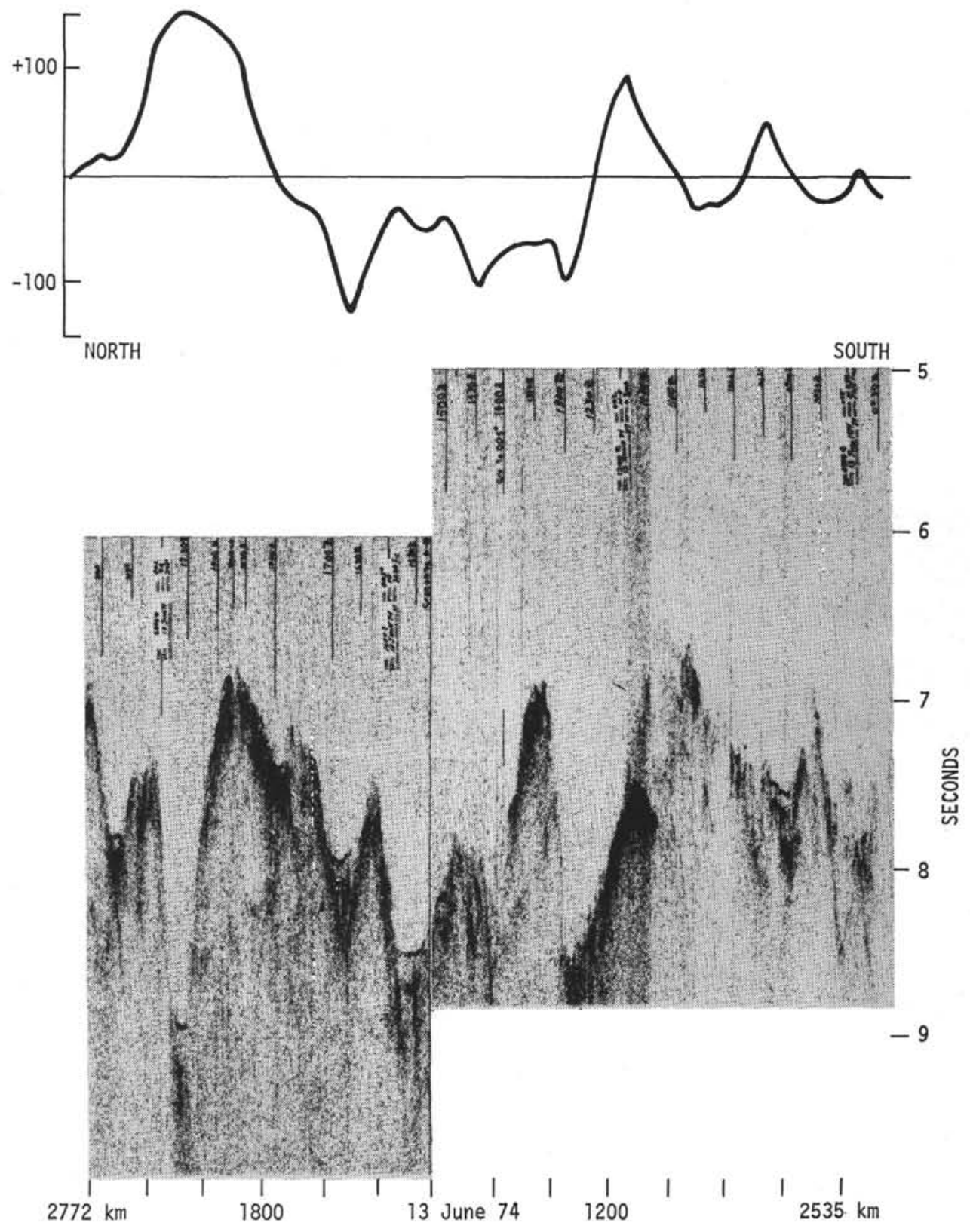

Figure 4. Glomar Challenger, Leg 37, seismic reflection and magnetic anomaly profiles in vicinity of Kane Fracture Zone.

not correlate with bathymetric features and presumably represent polarity contrasts within oceanic basement.

An oblique crossing of the Mid-Atlantic Ridge Crest on the northern flanks of the Azores Plateau was made close to $0830 \mathrm{hr}, 23$ July (Figure 8). The thinning of sediments towards the median valley $(0830 \mathrm{hr})$ is clearly seen, as is a notable bilateral symmetry about the median valley in the bathymetry. Thus, the prominent ridges at $0030 \mathrm{hr}$ and $1300 \mathrm{hr}$ clearly match, as probably do the smaller ridge complexes centered on 0530 and $1030 \mathrm{hr}$. This bilateral symmetry in bathymetric features about a ridge crest is well known elsewhere and is reasonably interpreted in terms of episodic median valley volcanicity, with the ridges representing periods of rapid eruption with respect to lateral spreading rate. The concept of episodic volcanicity also provides an explanation for the distribution of basement paleomagnetic directions at the Leg 37 drilling sites. This section of ridge crest is marked by the largest magnetic anomalies encountered during Leg 37 . The central anomaly, 1 of Figure 8, is $2030 \gamma$ peak to peak, while several flanking anomalies are close to $1000 \gamma$ peak to peak. These large anomaly amplitudes are the consequence of the shallow depth of the ridge crest in this area, the floor of the median valley having a maximum depth of only 1430 meters. Symmetry in the magnetic anomaly pattern is not as well developed as it is in the bathymetry. Tentative identification of anomalies $2^{\prime}$ and ' 3 ' have been made. However, anomaly 1 , identified by its amplitude and location over the median valley, is very asymmetric with a deep negative trough at the south. Several explanations can be suggested for this asymmetry, although none can be tested from a single profile. The present spreading 


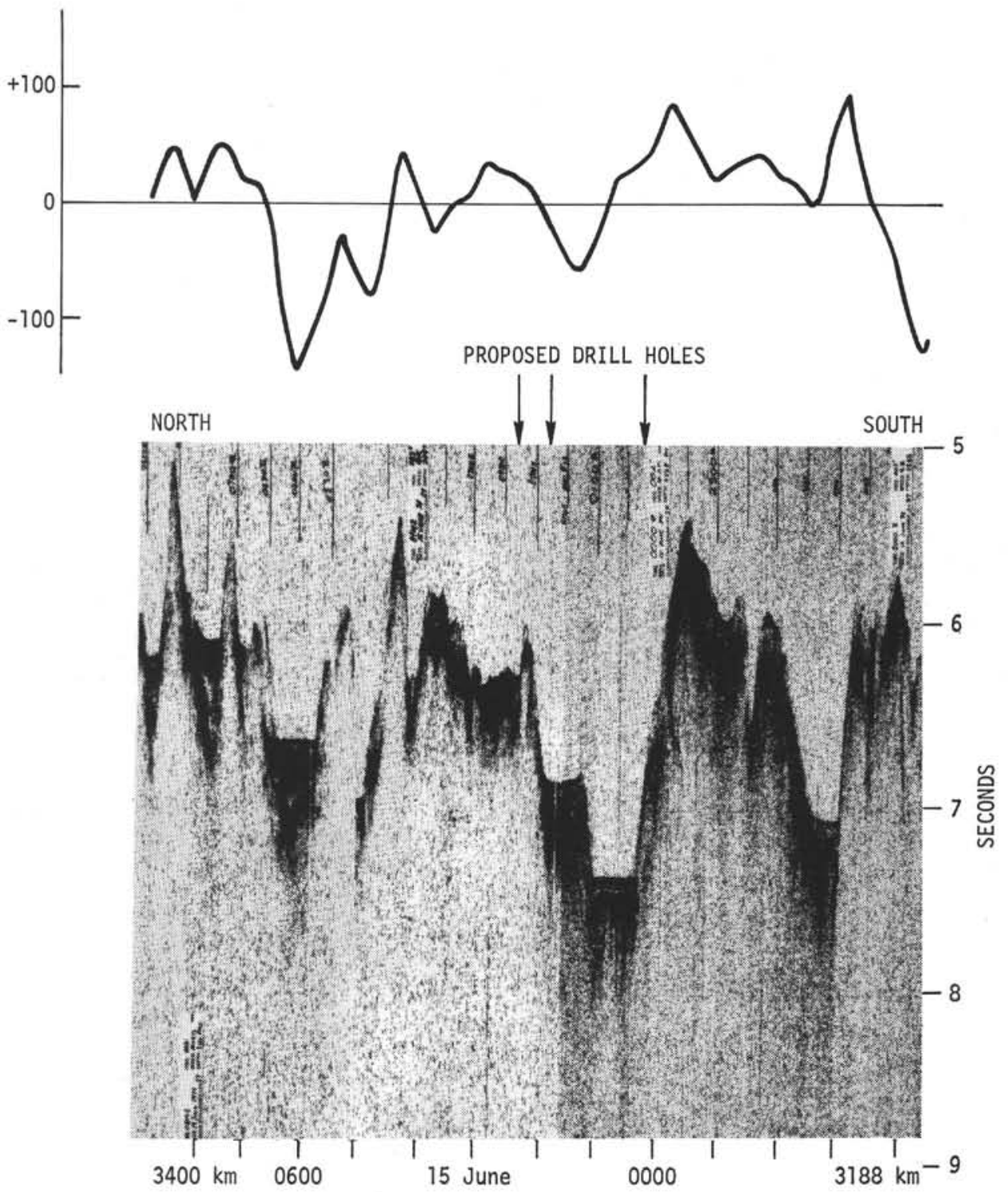

Figure 5. Glomar Challenger, Leg 37, seismic reflection and magnetic anomaly profiles in vicinity of Atlantis Fracture Zone.

center may strike well away from north-south or a small transform offset, perhaps located in the deepest southern side of the rift valley, may bring strongly magnetized, normally and reversely magnetized basalts into contact along an approximately east-west, vertical interface.

After crossing the ridge crest, the track of Glomar Challenger extended over increasingly older oceanic crust of the Eurasian plate. Between 0500 and $0730 \mathrm{hr}$ on 25 July the enigmatic Kings Trough feature was traversed (Figure 9). On our profile, which was made normal to the trough axis, the steep-sided depression has a width of close to $50 \mathrm{~km}$ and a maximum depth below the northeast wall of 2200 meters. On our section the more gentle southwest wall is largely covered with a veneer of sediment while the steeper northwest wall is sediment free. The ponded sediments in the deepest part of the trough show well-developed internal reflections in contrast to the single thick transparent layer draped over the basement surface outside the trough.
The magnetic signature of the trough is complex. A $250 \gamma$ positive anomaly located directly over the peak of the northeast wall must be a topographic effect and implies magnetization close to the present field direction for the uppermost basement in the vicinity. A similar topographic effect, complicated by adjacent withinbasement magnetic contrast, could explain the anomalies associated with the southwest wall.

The final feature of interest on the Leg 37 track is the contact between oceanic and continental crust seen to the southwest of Ireland (Figure 10). Here we see from right to left the termination of oceanic basement, at $0600 \mathrm{hr}, 27 \mathrm{July}$, a series of apparently faulted or slumped blocks between 0600 and $0800 \mathrm{hr}$, the steep continental slope between 0800 and $0930 \mathrm{hr}$, and a step until the continental shelf is reached at approximately $1745 \mathrm{hr}$. Two small submarine canyons situated on the northeastern edge of the step were crossed at 1600 and $1630 \mathrm{hr}$. Oceanic basement is covered by about $0.4 \mathrm{sec}$ (310 at $1.55 \mathrm{~km} / \mathrm{sec}$ velocity) of transparent, presuma- 

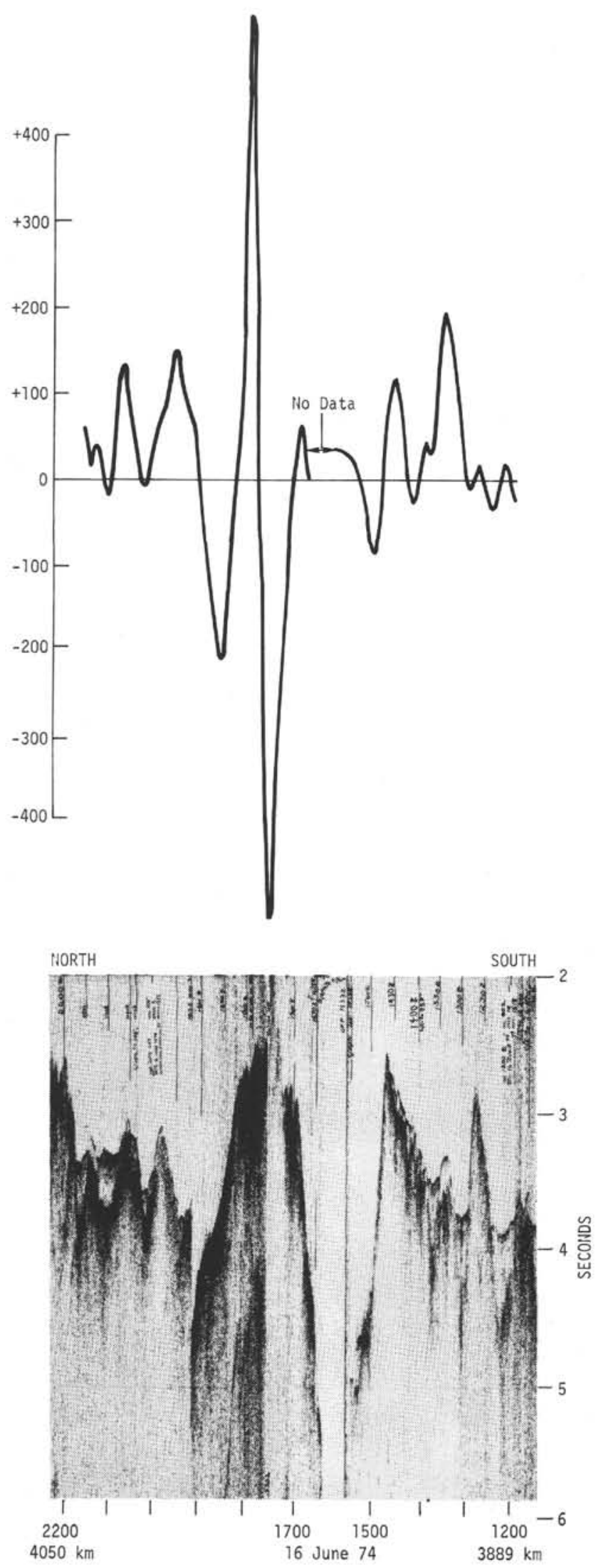

Figure 6. Glomar Challenger, Leg 37, seismic reflection and magnetic anomaly profiles in vicinity of Oceanographer Fracture Zone bly pelagic sediment. The step is underlain by multilayered reflecting horizons typical of sediments of continental origin, showing small but distinct structures of probable depositional and erosional origin to the maximum depth of penetration of about $0.7 \mathrm{sec}$. The slight rise at the seaward margin of the step bars this continental material from spilling out into the ocean basin. What appears to be a landwards wedging out of a member of the step's sedimentary sequence is seen at $1630 \mathrm{hr}, 0.44 \mathrm{sec}$ penetration. The magnetic profile shows an interesting relationship to bathymetry and geological province. Rather small amplitude anomalies of typical oceanic wavelengths occur over oceanic basement. These terminate with a relatively prominent anomaly, of $400 \gamma$ peak to peak amplitude, that is exactly coincident with the termination of clearly undisturbed oceanic basement at $0600 \mathrm{hr}$. The continental slope and peripheral $40 \mathrm{~km}$ of the step are marked by a series of anomalies of similar amplitude but longer wavelength than the typical oceanic anomalies. Continuing towards Ireland the next $75 \mathrm{~km}$ of step are marked by a gradual increase in field intensity; in terms of the total field measurements the rate of increase is rather greater than the rate of increase of the dipole field. The final $60 \mathrm{~km}$ of the upper step and shelf are marked by a sequence of anomalies that are not dissimilar to the anomalies associated with oceanic crust. We interpret the spatial variation in anomaly character in the following way:

1) Oceanic crust: Anomalies are due to polarity contrast within continuous basic oceanic layer.

2) Contact between oceanic and continental crust at $0600 \mathrm{hr}$. The prominent anomaly and change in field level is due to the sharp contrast between the magnetization of the two types of basement.

3) Small amplitude, long wavelength anomalies from 0630 to $1130 \mathrm{hr}$ : It is tempting to suggest that these are due to dispersed basic intrusions within continental crust, dating from the initial opening of this segment of the North Atlantic.

4) $75 \mathrm{~km}$ zone of gradual increase in field level: A thick sediment cover overlies continental basement, with and within-basement magnetic contrasts too distant to be resolved.

5) Inner zone of short wavelength anomalies: Continental basement has risen sufficiently near the surface for within-basement magnetic contrasts to be resolved.

\section{ACKNOWLEDGMENTS}

We would like to acknowledge the technical staff aboard Glomar Challenger during DSDP Leg 37 for their expert operation of the underway survey equipment. Robert Gerstein was kind enough to assist with the reduction of the magnetic data.

\section{REFERENCES}

Detrick, R.S. and Lynn, W.S., 1975. The origin of high amplitude magnetic anomalies at the intersection of the Juan de Fuca Ridge and the Blanco Fracture Zone: Earth. Planet. Sci. Lett. v. 26, p. 105-113.

Uchupi, E., 1971. Bathymetric Atlas of the Atlantic Caribbean and Gulf of Mexico, Woods Hole Oceanographic Institution, Reference No. 71-72, unpublished manuscript. 

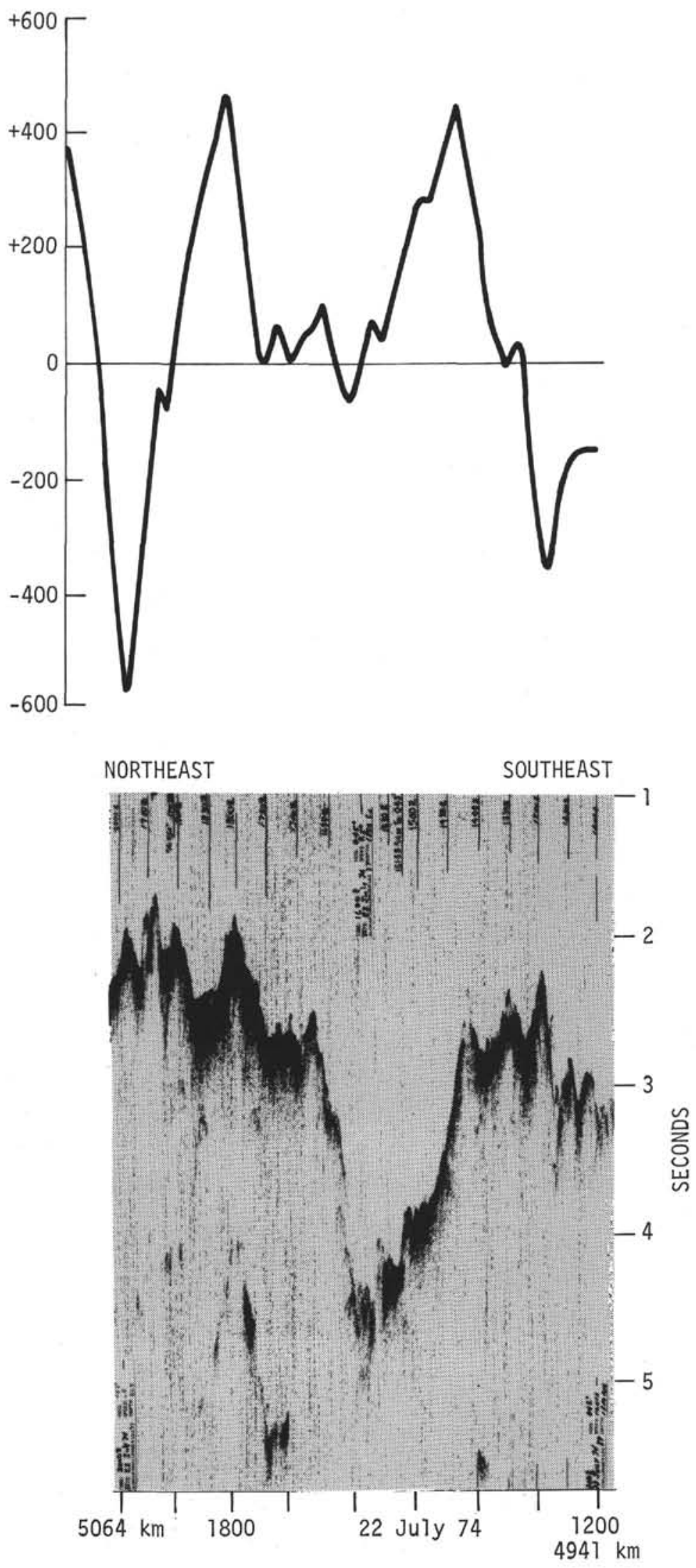

Figure 7. Glomar Challenger, Leg 37, seismic reflection and magnetic anomaly profiles in vicinity of Pico Fracture Zone. 
R. J. IULIUCCI, J. M. HALL, W. G. MELSON
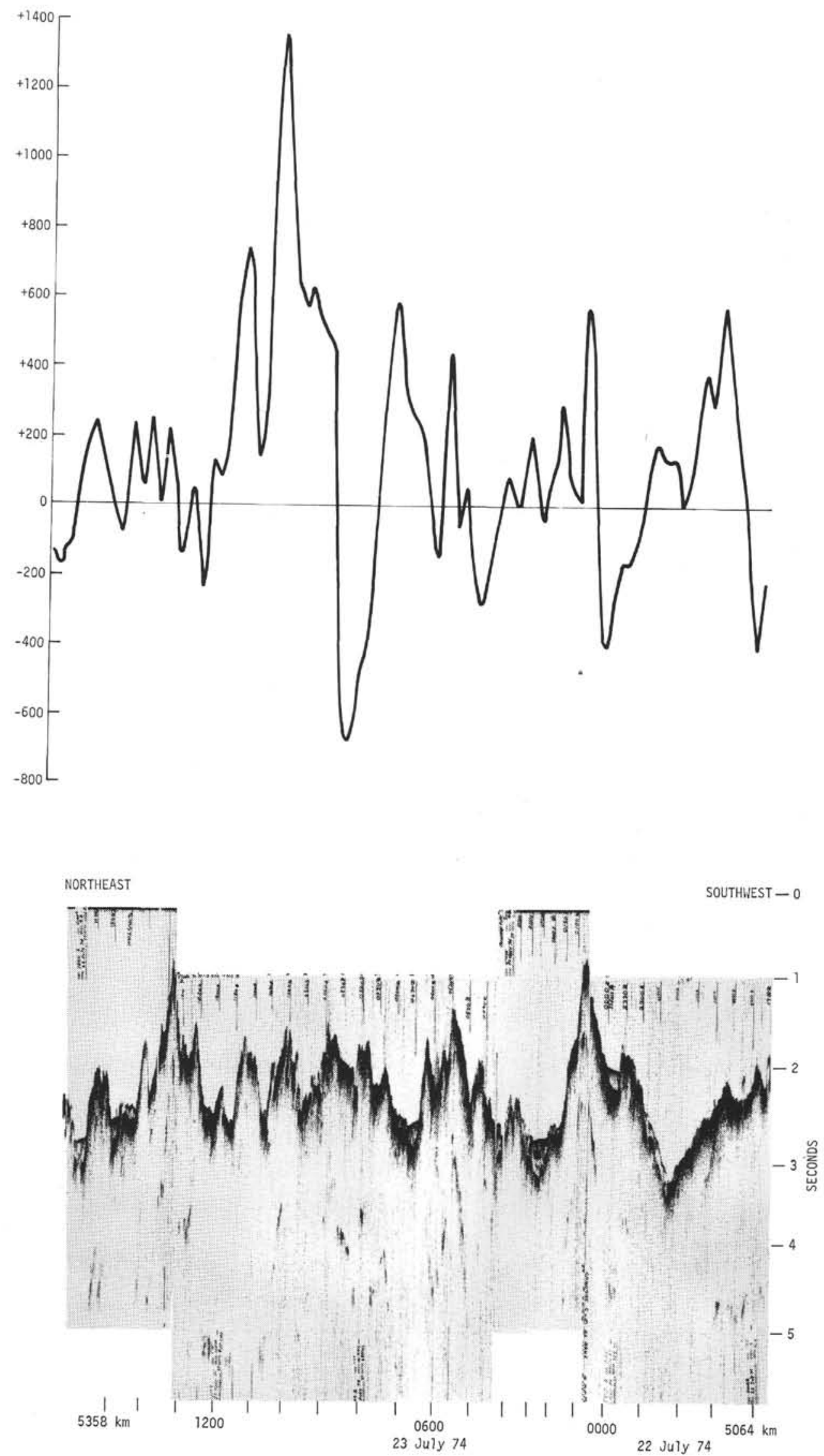

Figure 8. Glomar Challenger, Leg 37, seismic reflection and magnetic anomaly profiles in vicinity of Ridge Crest off Azores. 

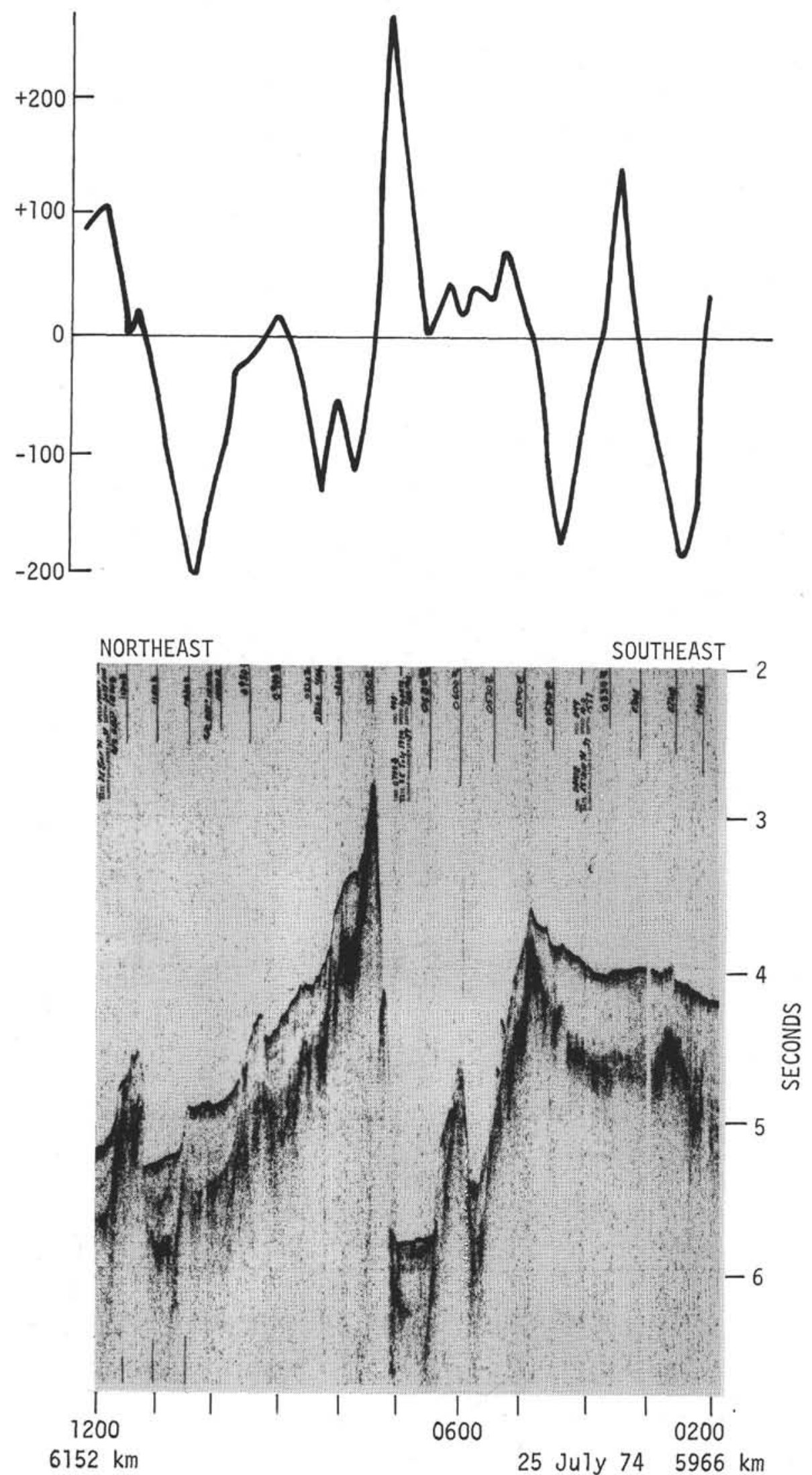

Figure 9. Glomar Challenger, Leg 37, seismic reflection and magnetic anomaly profiles in vicinity of King's Trough. 
R. J. IULIUCCI, J. M. HALL, W. G. MELSON
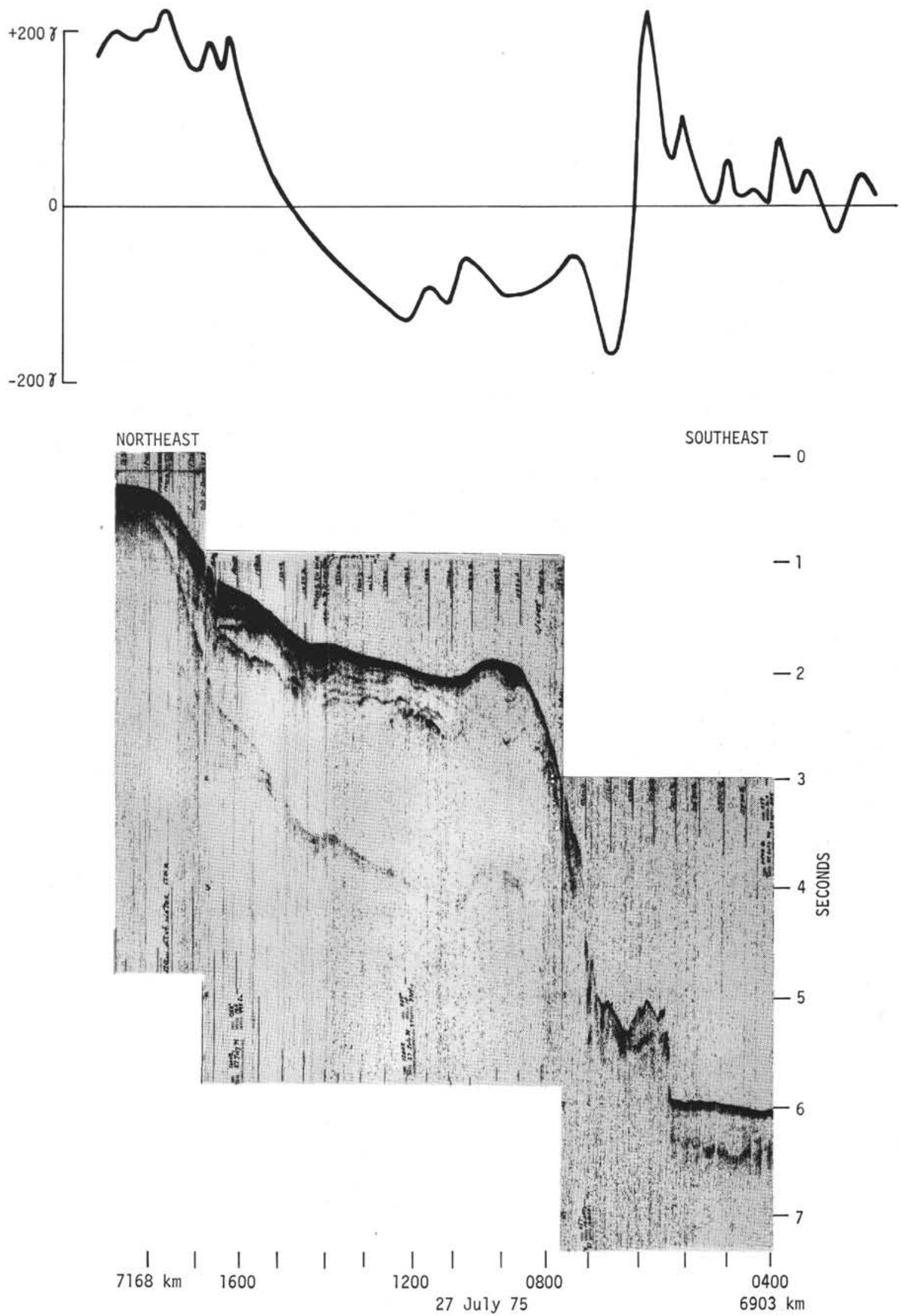

Figure 10. Glomar Challenger, Leg 37, seismic reflection and magnetic anomaly profiles in vicinity of Continental Slope at $50^{\circ}$ North latitude. 